\title{
RMetS
}

Royal Meteorological Society

\section{Diurnal equilibrium convection and land surface-atmosphere interactions in an idealized cloud-resolving model}

\author{
Linda Schlemmer ${ }^{\mathrm{a}}{ }^{\star}$ Cathy Hohenegger, ${ }^{\mathrm{b}}$ Juerg Schmidlia and Christoph Schär ${ }^{\mathrm{a}}$ \\ ${ }^{a}$ Institute for Atmospheric and Climate Science, ETH Zurich, Switzerland \\ ${ }^{\mathrm{b}}$ Max-Planck-Institute for Meteorology, Hamburg, Germany
}

\begin{abstract}
${ }^{*}$ Correspondence to: L. Schlemmer, Institute for Atmospheric and Climate Science, ETH Zurich, Universitaetsstrasse 16, CHN L16.1, Zurich 8092, Switzerland. E-mail: linda.schlemmer@alumni.ethz.ch
\end{abstract}

The influence of soil moisture and atmospheric stability on mid-latitude diurnal convection and land-atmosphere exchange is investigated in an idealized cloudresolving modelling framework using a full set of parametrization schemes. In each member of a series of month-long experiments, the model attains a state where deep, precipitating convection is triggered every day. This state is referred to as equilibrium diurnal convection. The triggering occurs via different mechanisms depending on the atmosphere-soil setting. In our framework latent heat fluxes comprise the primary control over the precipitation amounts. We find that evaporation is regulated by the availability of energy on the one hand and the availability of soil moisture and the near-surface saturation deficit of the atmosphere on the other. Increased cloud cover over wet soils reduces net short-wave radiation but increases net long-wave radiation, leading to a near-compensation of the two effects on available energy. Increased boundary layer moisture is removed by deep convection, thus increasing the near-surface saturation deficit and preventing a negative feedback of boundary layer moisture content on the latent heat fluxes. We also find that there is a spatial correlation between soil moisture and precipitation anomalies, suggesting that the soil moisture precipitation feedback acts on a scale of 10-50 km. Copyright (c) 2012 Royal Meteorological Society

Key Words: convection; cloud-resolving modelling; land-surface atmosphere interactions

Received 2 February 2011; Revised 21 December 2011; Accepted 22 December 2011; Published online in Wiley Online Library 15 February 2012

Citation: Schlemmer L, Hohenegger C, Schmidli J, Schär C. 2012. Diurnal equilibrium convection and land surface-atmosphere interactions in an idealized cloud-resolving model. Q. J. R. Meteorol. Soc. 138: 1526-1539. DOI:10.1002/qj.1892

\section{Introduction}

The interaction of the land surface with the atmosphere is an important element of the climate system and includes multiple processes and feedback mechanisms. It is well known that drought or precipitation events may be amplified by persistent soil moisture anomalies (Enthekabi et al., 1992; Seneviratne et al., 2006; Fischer et al., 2007a, 2007b). Whether a certain state of the soil can persist over longer time-scales is controlled by the strength of the land-atmosphere coupling. In regions where soils are close to saturation, evapotranspiration (ET) is controlled by the available net radiation. In dry regions, in contrast, the availability of soil moisture controls ET and anomalies are able to persist over longer time-scales (Koster et al., 2004; Dirmeyer et al., 2009). Concerning the availability of net radiation, on the one hand, an increase in cloud cover over wet soils reflects incoming radiation, thereby acting as a negative control on net short-wave radiation. On the other hand, net outgoing long-wave radiation may be trapped by clouds and water vapour, acting as an amplifying mechanism. An overall slightly positive effect has been reported by some previous studies (e.g. Eltahir, 1998; Schär et al., 1999). 
The question of whether the occurrence of precipitation is favoured over wet or dry soils is of utmost importance for the climate. Several studies describe that the occurrence of subsequent precipitation is linked to soil moisture (D'Odorico and Porporato, 2004) or evaporative fraction (Findell et al., 2011), but not subsequent precipitation amount. Alfieri et al., (2008), in contrast, detected a relatively weak feedback between soil moisture and the frequency of occurrence of precipitation that could both be positive or negative. From a water budget perspective one would nevertheless argue that more ET must lead to larger precipitation amounts on large space- and timescales. On small scales precipitation occurrence and amount are, however, not only controlled by the amount of water that is evaporated into the atmosphere but also by large-scale processes and numerous boundary layer processes and interactions among them. A stabilization of the atmosphere over wet soils can, for instance, result in a negative soil moisture precipitation feedback. Over southern Africa it was found that wet soils can lead to a stronger atmospheric stratification and to the formation of anticyclonic circulations that induce subsidence and divergence at the surface. The subsiding motion suppressed convective activity and precipitation, representing a negative soil moisture precipitation feedback (Cook et al., 2006). For summertime moist convection over land in Europe a similar stabilization of the atmospheric profile over wet soil was described in Hohenegger et al. (2009). Furthermore, they found different signs of the soil moisture-precipitation feedback in simulations using parametrized convection and simulations using explicitly resolved convection. A peculiar feature of their simulation was the presence of a stable layer that developed in the convection-permitting simulations over wet soils and inhibited the triggering of deep convection, resulting in reduced precipitation amounts over wet soils.

On seasonal time-scales mostly a strong positive correlation between soil moisture and evaporation and a positive correlation between soil moisture and atmospheric recycling ratio, implying a positive soil moisture-precipitation feedback, was found for western Africa (van den Hurk and van Meijgaard, 2010).

Whether precipitation occurs or not is often decided by the triggering of deep convection. As described in Schär et al. (1999), the growth of the planetary boundary layer (PBL) will be slower over wet soils than over dry soils, concentrating the moist entropy flux into a shallower layer, leading to higher values of convective available potential energy. Findell and Eltahir (2003a) explored different triggering mechanisms over dry soils -where boundary layer growth will occur -and wet soils, where a moistening of the atmosphere leads to a fall in the level of free convection (LFC). The stability and the humidity content of the atmosphere determine whether convection is triggered. Strongly sheared winds or winds that show a backing with height, leading to cold air advection in the lower troposphere, can, furthermore, suppress the triggering of convection (Findell and Eltahir, 2003b).

At small spatial scales inhomogeneities in the land cover (Brown and Arnold, 1998) or soil moisture inhomogeneities can have a decisive influence on the development of convective events (Emori, 1998). Taylor et al. (2010) investigated the importance of anomalies of the land surface in the generation of convergence zones that can lead to the initiation of storms in the Sahel zone.

A further important aspect for precipitation to occur is the formation of clouds. Ek and Mahrt (1994) and Ek and Holtslag (2004) focused on the development of clouds at the top of the PBL and found a more rapid increase of the relative humidity at the top of the PBL over drier soils and weak atmospheric stratifications due to the rapid deepening of the PBL. In the case of a strong stratification of the atmosphere, wet soils lead to larger relative humidities at the PBL top via a direct moistening of the PBL.

Turbulent fluxes from the surface, which link the soil to the atmosphere, can, moreover, be strongly modified by several boundary layer processes. The importance of freetropospheric humidity content and dry-air entrainment on the evolution of surface heat fluxes and the evolution of the PBL has been pointed out by Santanello et al. (2007) and van Heerwarden et al. (2009). The entrainment of dry air promoted by a growth of the PBL acts to dry the PBL and thereby to enhance latent heating. The importance of a developing nocturnal residual layer under dry freetropospheric conditions in the formation of droughts is pointed out by Santanello et al. (2007). Most of these studies focused on a short time-scale and investigated merely whether cloud formation occurred or precipitation was triggered. They did not investigate resulting impacts upon precipitation amounts or the behaviour over several days.

In our study we analyse the interplay between the surface, the convective boundary layer and the deep atmosphere over numerous diurnal cycles in an idealized cloud-resolving model with a full set of parametrizations. We investigate the longer-time behaviour of the system, where the atmosphere is in equilibrium with a specific soil moisture distribution. Our focus lies on the evolution of the diurnal cycle of moist convection with different soil moisture contents and atmospheric stabilities. Our modelling framework has been introduced in Schlemmer et al. (2011) and used to investigate the sensitivity of the diurnal cycle of moist convection to atmospheric moisture and stability. It was found that in a certain regime, referred to as diurnal equilibrium, the prescribed moisture content of the atmosphere has negligible influence, as it is determined by the convection itself. The stability of the atmosphere determines the depth of the evolving convection and the timing of the precipitation peak. The total amount of precipitation, however, is largely unchanged as it is controlled by ET.

In the current study we expand the work of Schlemmer et al. (2011) by additionally varying the soil moisture content and thereby ET. The simulations mimic the conditions during convectively active flat-pressure synoptic situations, which may persist over several days in midlatitude regions, as for example in July 2006 over mid Europe (Hohenegger et al., 2008) or in summertime in the southeastern USA (Garrett, 1982). Sensitivity of precipitation to soil moisture appears to be large in such conditions.

The paper is organized as follows: in section 2 we review the framework and the model and give, moreover, a short theoretical consideration on what we expect for the soil moisture-precipitation feedback in the diurnal equilibrium. In section 3 we present simulations with varied parameters and conduct sensitivity studies on the specific model set-up used. In section 4 we discuss the limitations of our framework and in section 5 we summarize the work performed. 


\section{Experimental set-up}

The numerical framework used has been introduced in Schlemmer et al. (2011) and we briefly summarize the most important concepts here.

The framework applies to situations where the soil-atmosphere system reaches a state of diurnal equilibrium. In the real world, flat-pressure synoptic situations, where a state of diurnal equilibrium evolves, can be present over a period of 1-2 weeks and our framework can be thought to describe an asymptotic limit to these situations. The framework is designed in such a way that the water balance is maintained by the system. This implies that any increase of ET has to be balanced by other processes, as detailed in the following (section 2.3). Therefore, it cannot represent situations where a replacement of the humidified air masses by large-scale processes occurs.

\subsection{Model description}

The simulations are performed with version 4.0 of the COSMO-CLM (Consortium for Small-Scale Modeling Model in Climate Mode; hereafter CCLM). The CCLM is a versatile limited-area atmospheric modelling system including a whole suite of model parametrizations (Steppeler et al., 2003; Doms and Förstner, 2004; Baldauf et al., 2011). It is based on the non-hydrostatic compressible atmospheric equations, uses the split-explicit time-stepping scheme (Klemp and Wilhelmson, 1978; Wicker and Skamarock, 2002), and is suited to applications with horizontal grid spacings from about $100 \mathrm{~m}$ to $100 \mathrm{~km}$. The model is run with a full set of parametrizations, except for convection, which is explicitly resolved. For more details on the employed parametrizations, the reader is referred to Schlemmer et al. (2011). We use a horizontal grid spacing of $\Delta x=2.2 \mathrm{~km}$ with $100 \times 100$ grid points in the horizontal and 50 vertical levels. Double-periodic lateral boundary conditions are employed. The Earth's rotation is neglected, as in many other cloud-resolving modelling studies (e.g. Su et al., 1999).

\subsection{Framework}

\subsubsection{Atmosphere}

We simulate diurnal convection over land, where moist convection interacts with the large-scale synoptic forcing as well as boundary layer, radiative and land surface processes. In our modelling framework the large-scale forcing is represented by relaxing the simulated atmosphere towards an externally prescribed profile, while the other processes are explicitly simulated.

The elevation of the surface is set to $489.0 \mathrm{~m}$ corresponding to the altitude of Munich. Incoming solar radiation is determined according to $48.25^{\circ} \mathrm{N}$ and $0^{\circ} \mathrm{E}$ on 12 July throughout the whole simulation. The model is initialized with a single vertical sounding prescribing the variables pressure, temperature, specific humidity and the horizontal wind components. White noise is applied to the initial temperature at the lowest layer with a maximum amplitude of $\pm 0.02 \mathrm{~K}$, to break the symmetry of the initial state. The model is run for 30 days, where days 16-30 of the simulation are used for the evaluation.
We relax the mean model state towards the prescribed atmospheric profiles using a height-dependent strength of the relaxation with weak (strong) relaxation in the lower (upper) troposphere. Similarly, soil moisture is relaxed weakly (strongly) in the upper (lower) soil (see below). This set-up enables the soil-atmosphere interface to develop freely, i.e. the diurnal boundary layer and convection develop in response to the solar forcing and are not strongly affected by the relaxation.

The height-dependent relaxation is implemented by an additional term that is added to the right-hand side of the prognostic equations:

$$
\frac{\partial X}{\partial t}=\left(\frac{\partial X}{\partial t}\right)_{\text {physical terms }}-\frac{\bar{X}-X_{\mathrm{ref}}}{\tau} \cdot f(p),
$$

where $X$ stands for temperature, specific humidity, or zonal or meridional wind, $X_{\text {ref }}$ are the values of the reference profile, $\bar{X}$ domain-mean values of the predicted variables and

$$
f(p)=0.5 \cdot\left(1+\operatorname{erf}\left(\frac{p_{0}-p}{b}\right)\right)
$$

where $p$ is pressure and erf is the error function, defined as: $\operatorname{erf}(x)=\frac{2}{\sqrt{\pi}} \int_{0}^{x} e^{-t^{2}} \mathrm{~d} t$. We set $p_{0}$ to $500 \mathrm{hPa}$ and $b$ to 300 $\mathrm{hPa}$. A relaxation parameter $\tau$ of 1 day is chosen, implying relaxation times of 2 days and 61 days at the 500 and $950 \mathrm{hPa}$ level, respectively. Note that such a relaxation could play some role in the simulated upper-level clouds, and therefore on the magnitude of the surface cloud-radiative impact. This is, however, in agreement with the process of advection that the additional term incorporates.

The profiles used to initialize the atmosphere are shown in Figure 1(a). The same profiles are also used as reference profiles in Eq. (1). To investigate the role of the temperature stratification for the land-atmosphere coupling, three different profiles for temperature are used:

- STABLE: $\mathrm{d} T \mathrm{~d} z^{-1}=-0.6 \mathrm{~K}(100 \mathrm{~m})^{-1}$

- CTL: $\mathrm{d} T \mathrm{~d} z^{-1}=-0.7 \mathrm{~K}(100 \mathrm{~m})^{-1}$

- UNSTABLE: $\mathrm{d} T \mathrm{~d} z^{-1}=-0.8 \mathrm{~K}(100 \mathrm{~m})^{-1}$

Values for convective available potential energy (CAPE) and convective inhibition (CIN) for the input profiles are given in Table 1.

Since the relaxation is strong in the upper troposphere and tropopause region, upper-tropospheric temperature stays distinct between simulations using different stabilities, but equal for simulations with differing soil moisture but the same atmospheric stability. In the lower troposphere the model is able to simulate its own state, resulting in diurnal cycles depending upon soil moisture content and uppertropospheric stability and humidity (compare Figure 4 in Schlemmer et al., 2011).

\subsubsection{Soil}

To simulate the interactions between the atmosphere and the underlying soil, the multilayer soil model TERRA_ML after Heise et al. (2003) with 10 layers is used with a total depth of $11.5 \mathrm{~m}$. Layer thickness varies from $1 \mathrm{~cm}$ at the surface to $7.5 \mathrm{~m}$ in the deep soil. The upper seven soil layers down to a depth of $1.47 \mathrm{~m}$ are hydrologically active. The 

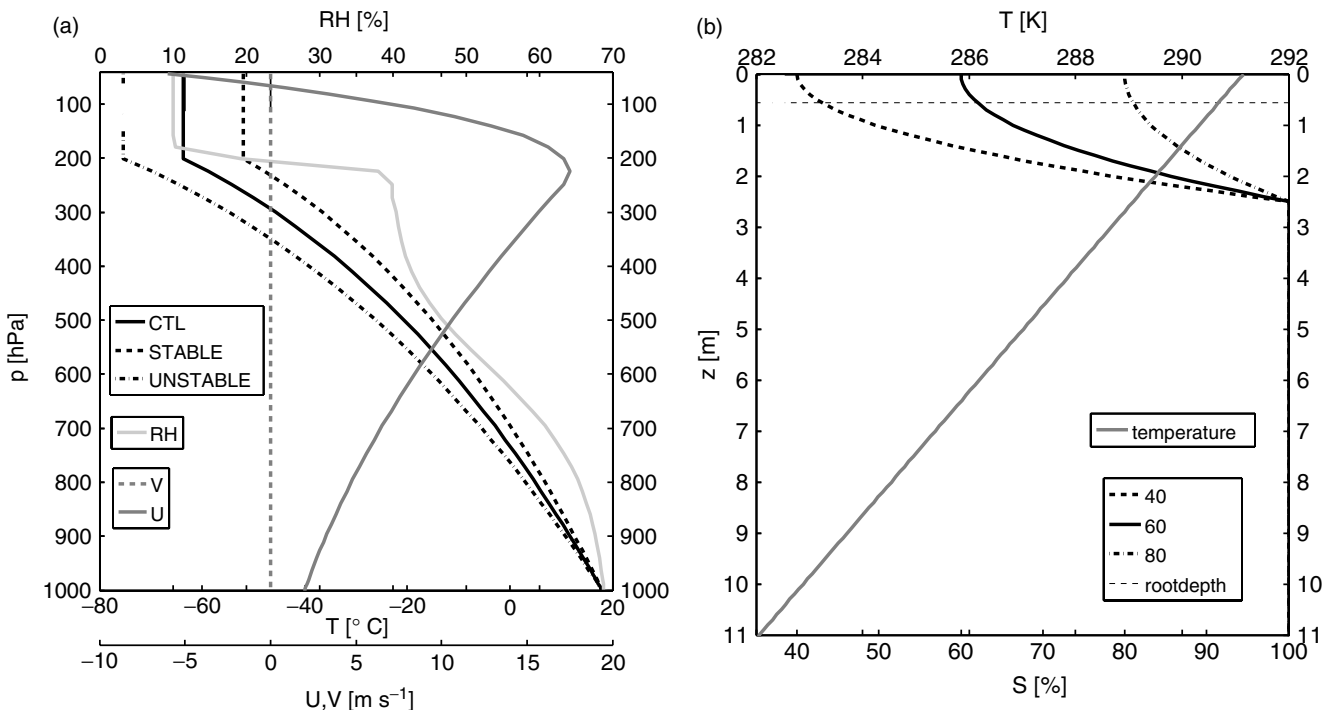

Figure 1. Input and reference profiles of (a) temperature $\left({ }^{\circ} \mathrm{C}\right.$ ) for STABLE (black dashed line), CTL (black solid line) and UNSTABLE (black dash-dotted line), relative humidity (\%, light grey line), zonal wind $\left(\mathrm{m} \mathrm{s}^{-1}\right.$, solid dark grey line), meridional wind ( $\mathrm{m} \mathrm{s}^{-1}$, dashed dark grey line) and (b) soil moisture saturation (\%, black lines), root depth ( $\mathrm{m}$, thin dashed line) and soil temperature (K, grey line).

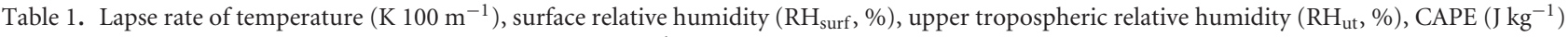
and $\mathrm{CIN}\left(\mathrm{J} \mathrm{kg}^{-1}\right)$ for the input/reference profiles used.

\begin{tabular}{|c|c|c|c|c|c|}
\hline Simulation name & $\begin{array}{c}d \mathrm{~T} / d \mathrm{z} \\
\left(\mathrm{K} 100 \mathrm{~m}^{-1}\right)\end{array}$ & $\begin{array}{c}\mathrm{RH}_{\text {surf }} \\
(\%)\end{array}$ & $\begin{array}{c}\mathrm{RH}_{\mathrm{ut}} \\
(\%)\end{array}$ & $\begin{array}{c}\text { CAPE } \\
\left(\mathrm{J} \mathrm{kg}^{-1}\right)\end{array}$ & $\begin{array}{c}\mathrm{CIN} \\
\left(\mathrm{J} \mathrm{kg}^{-1}\right)\end{array}$ \\
\hline STABLE & -0.6 & 70 & 40 & 0.0111 & 0.00 \\
\hline CTL & -0.7 & 70 & 40 & 344 & 31.1 \\
\hline UNSTABLE & -0.8 & 70 & 40 & 1740 & 10.3 \\
\hline STABLE_WET & -0.6 & 90 & 50 & 311 & 2.58 \\
\hline STABLE_DRY & -0.6 & 50 & 30 & 0.0115 & 0.0 \\
\hline
\end{tabular}

lowest three layers are climatological layers. The soil type is set to loam, consistent with the most commonly used soil type in CCLM. Vegetation is prescribed by specifying a leaf area index of 2.96, a plant cover of 0.84 and a root depth of $0.56 \mathrm{~m}$. The surface roughness is set to 0.04 $\mathrm{m}$. These settings represent typical values for European conditions. The land surface scheme considers infiltration, percolation, capillary movement, melting and freezing of snow, ET and runoff. ET, which is of key importance in controlling the feedback between soil moisture and convection, takes into account three source terms: bare soil evaporation, evaporation from the interception reservoir and transpiration from vegetation. The formulation closely follows the biosphere-atmosphere transfer scheme (BATS) (Dickinson, 1984). Potential evaporation is determined using a drag law approach:

$$
E_{\text {pot }}\left(T_{\text {sfc }}\right)=\rho C_{q}^{d}\left|\mathbf{v}_{\mathbf{h}}\right|\left(Q\left(T_{\mathrm{sfc}}\right)-q\right)
$$

where $T_{\text {sfc }}$ is the skin temperature, $\rho$ is the density of the atmosphere at the lowest atmospheric layer, $C_{q}^{d}$ is the bulkaerodynamic coefficient for turbulent moisture transfer at the surface, $q$ the specific humidity at the lowest atmospheric layer and $Q\left(T_{\text {sfc }}\right)$ the saturation specific humidity at the surface. Bare soil evaporation $E_{\mathrm{b}}$ is then determined using a supply-and-demand approach, where the smaller term of either the maximum flux of moisture $F_{\mathrm{m}}$ that the soil can sustain, or the potential evaporation is used. $F_{\mathrm{m}}$ is mainly a function of the average soil water content.
Evaporation from the interception reservoir is determined according to $E_{\mathrm{i}}=\min \left[\frac{\rho_{\mathrm{w}}}{\Delta t} W_{\mathrm{i}} ; f_{\mathrm{i}} E_{\text {pot }}\left(T_{\mathrm{sfc}}\right)\right]$, where $\rho_{\mathrm{w}}$ is the density of water, $W_{\mathrm{i}}$ is the water depth of the interception store and $f_{\mathrm{i}}$ is the partial coverage of the surface by interception water.

The biophysical control of plants on transpiration is considered via the stomatal resistance. For the formulation of the stomatal resistance $r_{\mathrm{s}}$ the multiplicative formulation by Jarvis (1976) is utilized. It takes into account the influence of radiation, water, temperature and atmospheric humidity by the $F$ functions as

$$
r_{\mathrm{s}}^{-1}=r_{\max }^{-1}+\left(r_{\min }^{-1}-r_{\max }^{-1}\right)\left[F_{\mathrm{rad}} F_{\mathrm{wat}} F_{\mathrm{tem}} F_{\mathrm{hum}}\right],
$$

with the parameters $r_{\min }=150 \mathrm{~s} \mathrm{~m}^{-1}$ and $r_{\max }=$ $4000 \mathrm{~s} \mathrm{~m}^{-1}$. The functions $F$ are 1 for optimal conditions and decrease to 0 for unfavourable conditions for plants. Most important for the following studies are the radiation function:

$$
F_{\text {rad }}=\min \left(1, \frac{\mathrm{PAR}}{\mathrm{PAR}_{\text {crit }}}\right)
$$

where PAR is the photosynthetically active radiation and $\mathrm{PAR}_{\text {crit }}=100 \mathrm{~W} \mathrm{~m}^{2}$ is a tuning parameter; and the dependency on soil water:

$$
F_{\text {wat }}=\max \left[0, \min \left(1, \frac{w_{l, \text { root }}-w_{\mathrm{PWP}}}{w_{\mathrm{TLP}}-w_{\mathrm{PWP}}}\right)\right] \text {, }
$$


where $w_{l, \text { root }}$ is the liquid water content fraction of the soil averaged over the root depth and $w_{\text {PWP }}$ is the permanent wilting point. The turgor loss point $w_{\mathrm{TLP}}$ is parametrized after Denmead and Shaw (1962):

$$
\begin{aligned}
w_{\mathrm{TLP}} & =w_{\mathrm{PWP}}+\left(w_{\mathrm{FC}}-w_{\mathrm{PWP}}\right) \\
\cdot & \left(0.81+0.121 \arctan \left(E_{\mathrm{pot}}\left(T_{\mathrm{sfc}}\right)-E_{\mathrm{pot}, \mathrm{norm}}\right)\right),
\end{aligned}
$$

where $E_{\text {pot,norm }}=4.75 \mathrm{~mm} \mathrm{~d}^{-1}$. In the 60_CTL simulation $E_{\text {pot }}\left(T_{\text {sfc }}\right) \approx 13 \mathrm{~mm} \mathrm{~d}^{-1}$ averaged over the diurnal cycle, which is relatively far away from $E_{\text {pot,norm. }}$ The turgor loss point of plants is therefore close to the field capacity.

In a regional climate model set-up the CCLM was found to adequately simulate latent heat fluxes but to underestimate sensible heat fluxes, leading to a bias in the Bowen ratio. This bias has partly been attributed to an underestimation of incoming solar radiation, due to an over-prediction of the cloud cover (Jaeger et al., 2009; Davin et al., 2011) and an unrealistically high aerosol optical depth (Zubler et al., 2011).

To initialize soil moisture an idealized profile is used, which increases quadratically from the surface value to saturation at a depth of $2.50 \mathrm{~m}$. To asses the impacts of soil moisture on the diurnal cycle of convection, simulations with relative surface soil moisture of $20 \%, 40 \%, 60 \%$ and $80 \%$, respectively, are performed. The different input profiles for soil moisture saturation are shown in Figure 1(b). For the loam soil $S=20 \%$ lies below the permanent wilting point, $S=40 \%$ and $60 \%$ are situated between the permanent wilting point and the field capacity, and $S=80 \%$ is above the field capacity. To restore water that is evaporated to the atmosphere or lost by surface and groundwater runoff, a relaxation equivalent to that used in the atmosphere is performed on soil moisture with a time constant of $\tau_{\text {soil }}=2$ days in the deep soil. The relaxation is weakest close to the surface and increases to full strength at the lowest hydrologically active layer (cf. Schlemmer et al., 2011). The concept here is comparable to that in the atmosphere: we wish to keep the model in the deep soil close to a specified state but allow the soil-atmosphere system to interact via surface fluxes of latent and sensible heat, boundary layer processes and deep convection.

\subsection{Budget considerations}

We briefly review what we expect from a theoretical perspective for the soil moisture-precipitation feedback in the diurnal equilibrium in our idealized framework. The energy balance at the surface reads

$$
\mathrm{SW}+\mathrm{LW}+E+H+G=0,
$$

where SW is the surface net short-wave radiation, LW is the surface net long-wave radiation, $E$ is the latent heat flux, $H$ is the sensible heat flux and $G$ the ground heat flux. $G$ is approximately zero averaged over the diurnal cycle, as soil temperatures show only a negligible trend after the first 15 days (see Figure 2(b)). For the water budget of the atmosphere $\frac{\partial W_{\text {atm }}}{\partial t}$ we can write:

$$
\frac{\partial W_{\mathrm{atm}}}{\partial t}=\frac{E}{L_{\mathrm{v}}}-P+R,
$$

where $L_{\mathrm{v}}$ is the latent heat of vaporization, $P$ is the surface rain rate and $R$ the moisture tendencies due to the relaxation. In the equilibrium, averaged over the diurnal cycle and the entire domain, the budget of the atmosphere is approximately closed $\left(\frac{\partial W_{\mathrm{atm}}}{\partial t} \approx 0\right)$. The values for the relaxation tendencies $R$ amount to roughly $20 \%$ of ET and the relaxation acts to dry the atmosphere. In the equilibrium, the remaining $80 \%$ of the evaporated water needs to be converted into precipitation, as in our framework there must be an approximate balance between ET and P.

For low soil moisture content, ET is below its potential rate $E_{\text {pot }}$ and a decrease of soil moisture leads to a decrease of ET. Therefore, a decrease of soil moisture must decrease precipitation, leading to a positive feedback.

For high soil moisture content (where the soil meets atmospheric demand and ET is at its potential rate) the only possible mechanism to end up in a negative soil moisture precipitation feedback in diurnal equilibrium is to decrease potential evaporation. This could happen via two different pathways. The first one is to reduce the available energy at the surface $Q=R_{n}-G$, e.g. through cloud processes. The second pathway is to increase the moisture content of the boundary layer, thereby reducing the saturation deficit and $E_{\text {pot }}$. We will elucidate the role of the mentioned mechanisms for our idealized framework in the following section.

It should be stressed that the current simulations cannot be directly compared to the simulations of Hohenegger et al. (2009). An increase (decrease) of soil moisture in their cloud-resolving simulations did lead to larger (smaller) latent heat fluxes, but reduced (enhanced) precipitation amounts (see their Figure 6), which is characteristic for a transient phase, where the approximate balance between evaporation and precipitation is not necessarily given.

In our framework, atmospheric relaxation terms are largest for stable atmospheric conditions, and soil relaxation terms for a soil moisture saturation of $80 \%$ when significant runoff occurs. Without relaxation, the system changes quickly to another state under such conditions.

\section{Results}

Our goal is to understand the feedbacks and relevant processes in the coupled land surface-atmosphere system for different soil moisture contents and atmospheric stabilities. Therefore we perform simulations with combined changes in atmospheric stability (STABLE, CTL and UNSTABLE; see section 2.2.1) and volumetric soil water contents (20\%, $40 \%, 60 \%$ and $80 \%$; see section 2.2 .2 ), resulting in a set of 12 simulations. The naming of the simulations is as follows: the soil moisture is combined with the atmospheric stability, 60_STABLE for example means, that $S=60 \%$ and the STABLE atmospheric profile is used. The simulations are summarized in Table 2.

\subsection{Diurnal equilibrium}

The soil moisture profile attains an equilibrium state with the atmosphere as described in Schlemmer et al. (2011). For further illustration, soil moisture and soil temperature for days 16-30 of the simulations using the CTL atmospheric stability are shown in Figure 2. The upper soil layers show a pronounced diurnal cycle, the lower layers a considerably weaker one. Soil temperature shows a very weak trend of about $1 \mathrm{~K}$ per 15 days in the lowest active layer. 
Table 2. Mean daily precipitation amount $\left(\mathrm{mm} \mathrm{d}^{-1}\right)$, available energy $\left(\mathrm{Q}, \mathrm{W} \mathrm{m} \mathrm{m}^{-2}\right)$, latent $\left(E, \mathrm{~W} \mathrm{~m}^{-2}\right)$, sensible heat flux $\left(H, \mathrm{~W} \mathrm{~m} \mathrm{~m}^{-2}\right)$ and difference between evaporation and precipitation $\left(\mathrm{mm} \mathrm{d}^{-1}\right)$ for the main set of simulations.

\begin{tabular}{|c|c|c|c|c|c|}
\hline Simulation name & $\begin{array}{l}\text { Precipitation sum } \\
\quad\left(\mathrm{mm} \mathrm{d}^{-1}\right)\end{array}$ & $\begin{array}{c}Q \\
\left(\mathrm{~W} \mathrm{~m}^{-2}\right)\end{array}$ & $\begin{array}{c}E \\
\left(\mathrm{~W} \mathrm{~m}^{-2}\right)\end{array}$ & $\begin{array}{c}H \\
\left(\mathrm{~W} \mathrm{~m}^{-2}\right)\end{array}$ & $\begin{array}{l}E / L_{\mathrm{v}}-P \\
\left(\mathrm{~mm} \mathrm{~d}^{-1}\right)\end{array}$ \\
\hline 20_STABLE & 0.00 & 82 & 17 & 65 & 0.58 \\
\hline 40_STABLE & 1.94 & 149 & 106 & 42 & 1.74 \\
\hline 60_STABLE & 2.88 & 147 & 123 & 24 & 1.36 \\
\hline 80_STABLE & 3.43 & 150 & 134 & 16 & 1.21 \\
\hline 20_CTL & 0.03 & 92 & 12 & 80 & 0.40 \\
\hline 40_CTL & 2.00 & 145 & 104 & 41 & 1.58 \\
\hline 60_CTL & 3.36 & 159 & 129 & 30 & 1.11 \\
\hline 80_CTL & 3.82 & 159 & 141 & 18 & 1.06 \\
\hline 20_UNSTABLE & 0.06 & 96 & 9 & 87 & 0.27 \\
\hline 40_UNSTABLE & 2.27 & 143 & 97 & 47 & 1.07 \\
\hline 60_UNSTABLE & 3.41 & 162 & 130 & 32 & 1.08 \\
\hline 80_UNSTABLE & 3.99 & 165 & 144 & 21 & 1.00 \\
\hline
\end{tabular}

(a)

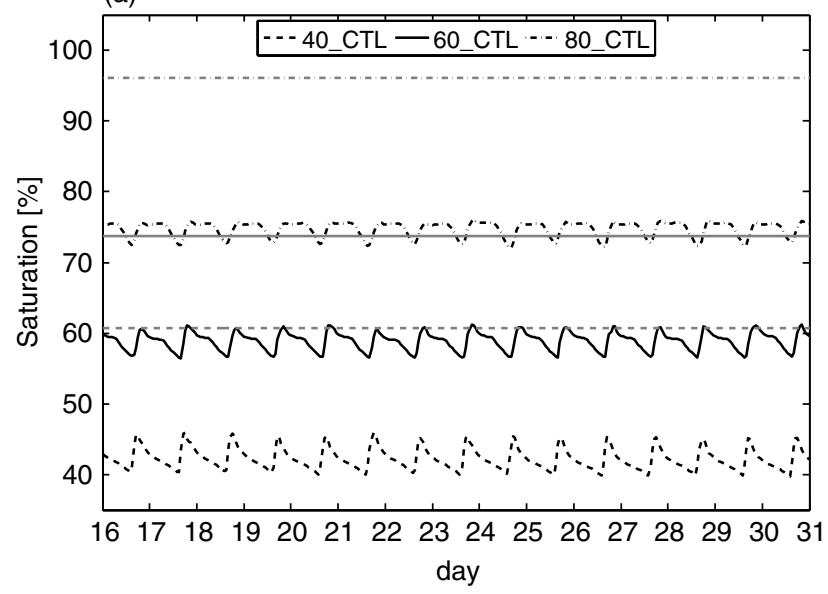

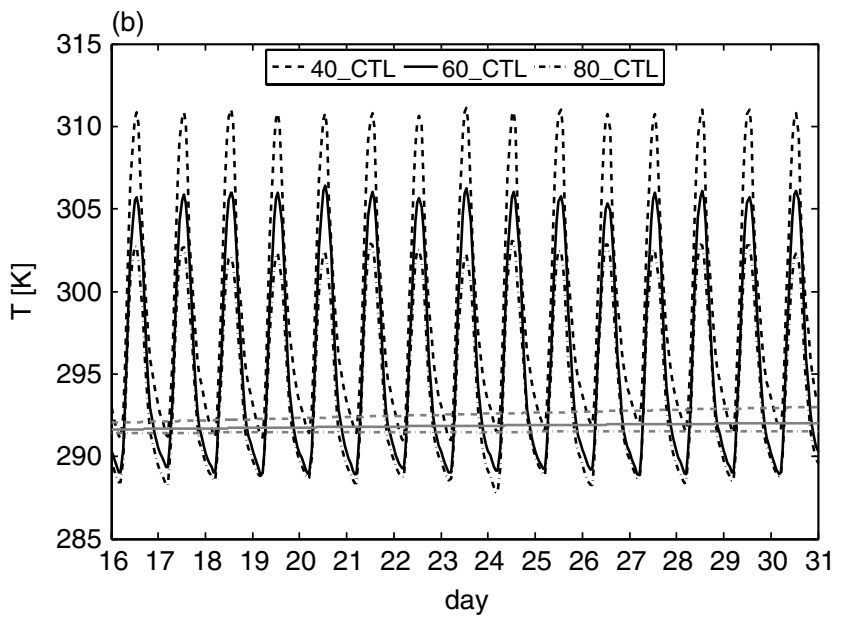

Figure 2. (a) Simulated soil moisture saturation (\%) and (b) soil temperature (K) for 40_CTL (dashed-line), 60_CTL (solid line) and 80_CTL (dash-dotted line) at the uppermost layer (black lines) and the lowest hydrologically active layer at a depth of $1.47 \mathrm{~m}$ (grey lines).

Figure 3 shows the mean diurnal cycle of cloud water, cloud ice and surface rain rate for the set of simulations, averaged over days 16-30 of the simulation. Remarkably, all simulations with $S \geq 40 \%$ show deep, precipitating convection. This means that the model gets into a diurnal equilibrium state where sufficient soil moisture is available to evaporate, trigger convection, condense and precipitate. Reducing $S$ further to $20 \%$ leads to an almost complete shut-off of clouds and precipitation, as the soil simply cannot evaporate sufficient moisture to form precipitation.

Going from more stable to more unstable atmospheric profiles, the period of rainfall is prolonged and the peak precipitation is shifted to later times. This phenomenon has been explained in Schlemmer et al. (2011) and can be understood by the accumulation of humidity in the PBL under stable conditions.

Over wetter soils, precipitation occurrence is additionally shifted to later times, and as expected precipitation amounts are increased, which constitutes a positive soil moisture-precipitation feedback within the present framework, in particular under the constraint of Eq. (8). Cloud bases and cloud tops are shifted to lower elevations, as expected from thermodynamic considerations. Also, persistent mid-level clouds (around $700 \mathrm{hPa}$ ) begin to appear, especially in the simulations 60_STABLE, 60_CTL, 80_STABLE, 80_CTL and 80_UNSTABLE. Their thickness increases with soil moisture and stability.
In comparison to stable conditions, unstable atmospheric profiles shift clouds tops to higher altitudes, more ice clouds are simulated, precipitation starts to fall later, and the time of the precipitation peak is shifted to later times, as found in Schlemmer et al. (2011). Changes in stability do not seem to impact the overall sign of the simulated soil moisture-precipitation feedback in our framework.

$Q$, ET and sensible heat fluxes are shown in Figure 4. $Q$ is of comparable magnitude in all simulations with $S \geq 40 \%$, with a slight decrease in 60_STABLE and 80_STABLE, where the mid-level clouds reflect incoming radiation, while increased long-wave downward radiation offsets this reduction only partly. For $S=20 \%$, increased long-wave radiation in the dry atmosphere leads to a reduction of the available energy. The first potential pathway into a negative soil moisture-precipitation feedback mentioned in section 2.3 is as a consequence not realized, as a significant reduction of available energy occurs over dry, but not over wet soils.

All simulations with $S \geq 40 \%$ have latent heat fluxes that are larger than sensible heat fluxes. The midday Bowen ratios are around 0.2 in 80_STABLE and 0.75 in 40_UNSTABLE. As seen in Figure 4, latent heat fluxes increase with increasing soil moisture as there is more moisture available for ET. Sensible heat fluxes decrease with increasing soil moisture as a larger portion of the available net radiation is passed into latent heating. 

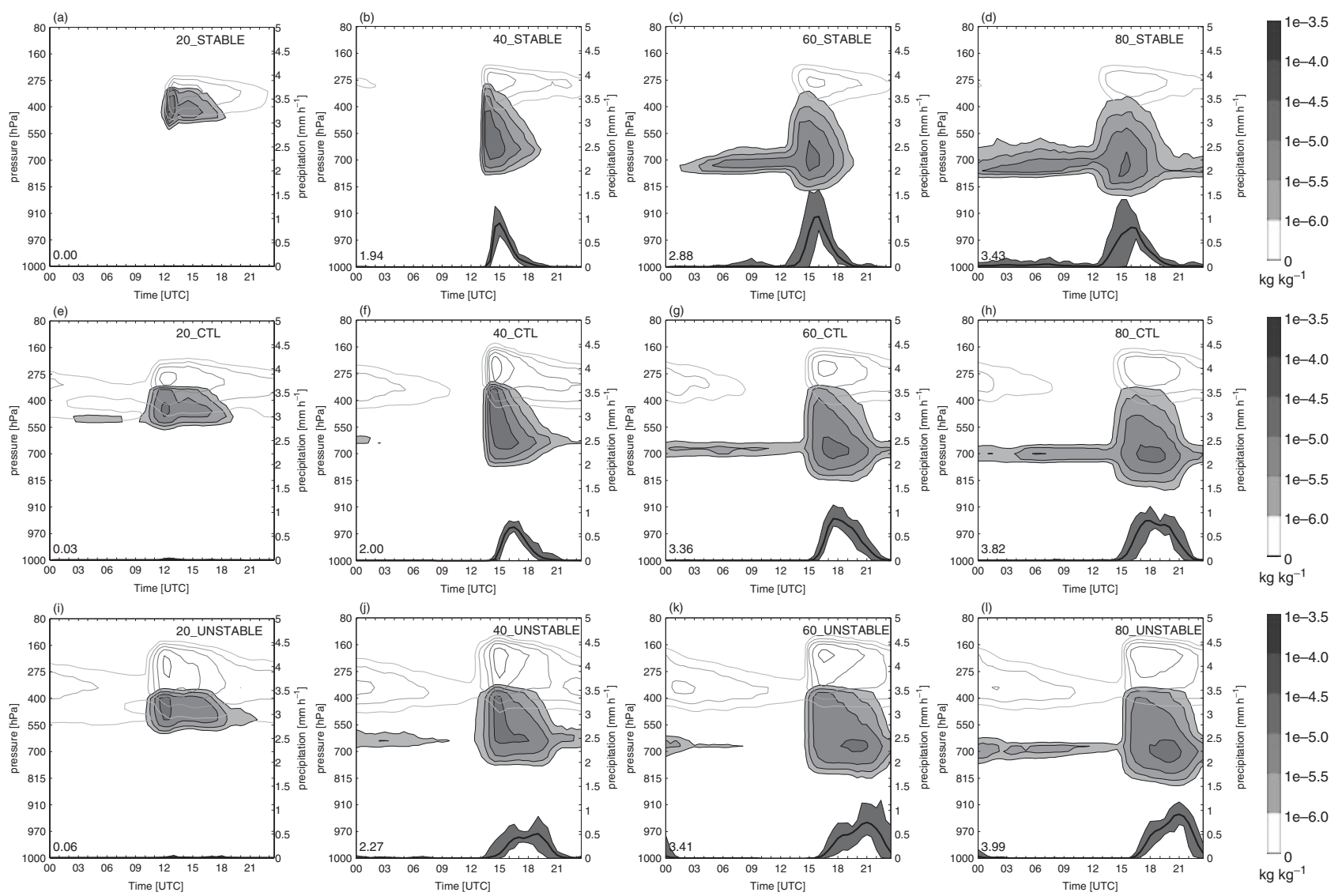

Figure 3. Mean diurnal cycles of cloud water content $\left(\mathrm{kg} \mathrm{kg}^{-1}\right.$, shaded area), cloud ice content ( $\mathrm{kg} \mathrm{kg}^{-1}$, contour lines) and domain mean precipitation $\left(\mathrm{mm} \mathrm{h}^{-1}\right.$, black solid line; minimum and maximum values over the 15 days of simulation are indicated by dark grey shading) for the set of 12 simulations. Numbers in the lower left corner indicate mean precipitation amounts averaged over day $16-30\left(\mathrm{~mm} \mathrm{~d}^{-1}\right)$. Panels (c), (g) and (k) are reproduced based on data from Schlemmer et al. (2011).
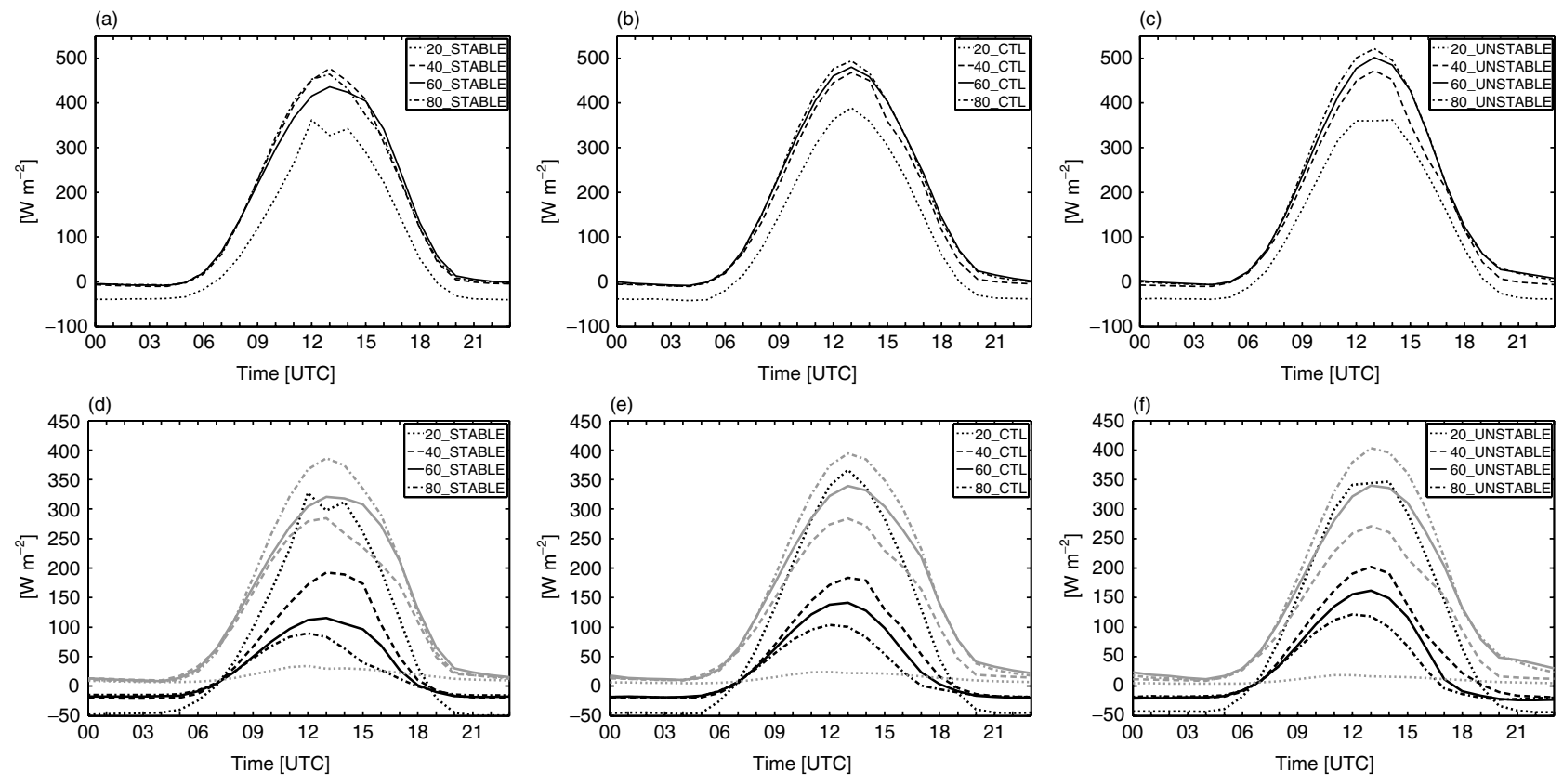

Figure 4. Upper row: mean diurnal cycles of available energy $\left(\mathrm{Q}, \mathrm{W} \mathrm{m}^{-2}\right)$; lower row: mean diurnal cycles of surface sensible (black lines) and latent (grey lines) heat fluxes $\left(\mathrm{W} \mathrm{m}^{-2}\right.$ ) for (a, d) STABLE, (b, e) CTL and (c, f) UNSTABLE for $20 \%$ (dotted line), 40\% (dashed line), 60\% (solid line) and 80\% (dash-dotted line) soil moisture saturation. 

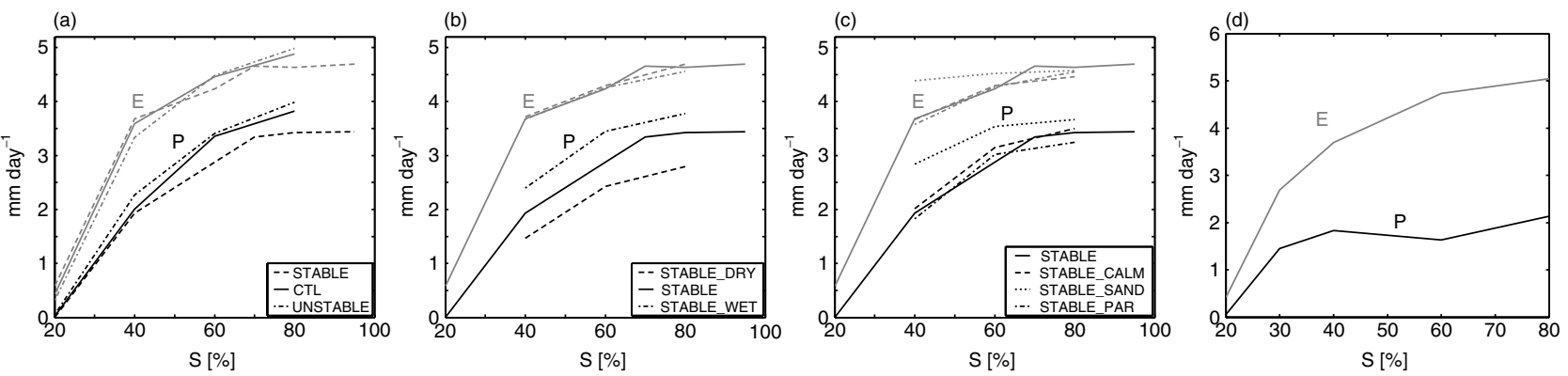

Figure 5. Mean precipitation amounts (black, $\mathrm{mm} \mathrm{d}^{-1}$ ) and evaporation (grey, $\mathrm{mm} \mathrm{d}^{-1}$ ) for days $16-30$ as a function of soil moisture for simulations (a) with different stability, (b) with different atmospheric humidities and (c) for additional sensitivity studies. Panel (d) shows mean precipitation amount (black, $\mathrm{mm} \mathrm{d}^{-1}$ ) and evaporation (grey, $\mathrm{mm} \mathrm{d}^{-1}$ ) averaged over days $1-3$ for the simulations CTL_UNSTABLE.
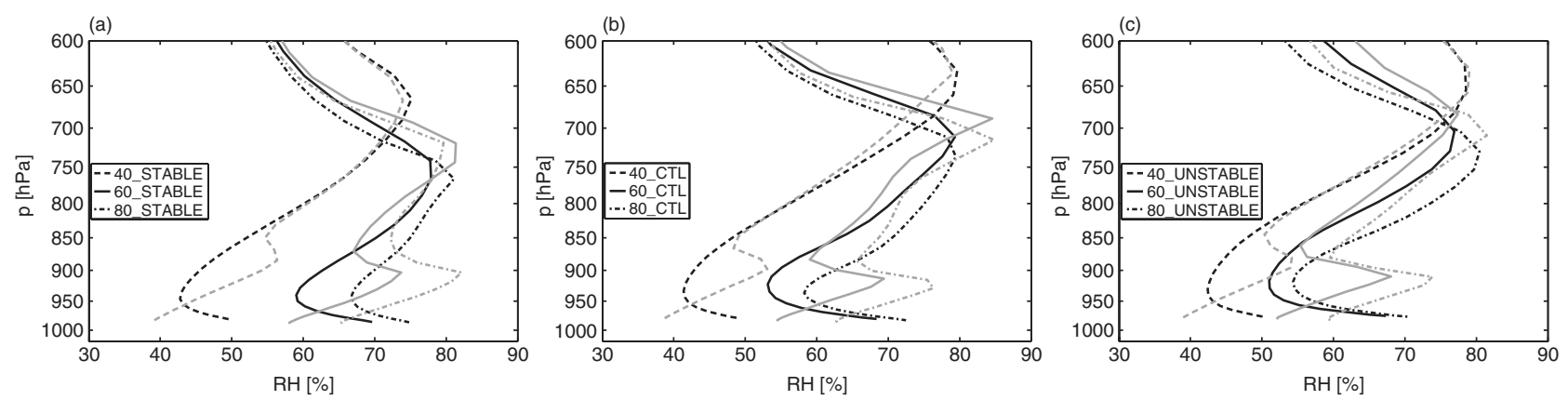

Figure 6. Domain mean profiles of relative humidity at 0000 (black lines) and 1200 UTC (grey lines) averaged over the 15 days of the simulations.

Since precipitation must approximately balance evaporation in the diurnal mean in our simulations (see section 2.3), the increase in latent heat fluxes with soil moisture leads to an increase in precipitation. Mean daily precipitation amounts and latent heat fluxes, averaged over the evaluation period, are summarized in Figure 5(a) and together with the sensible heat fluxes are shown in Table 2. For all atmospheric profiles, mean daily precipitation amounts increase with increasing soil moisture, indicative of a positive soil moisture-precipitation feedback. The increase is smallest for STABLE, due to the more pronounced cloud cover.

The experiments have been repeated with an even more stable atmosphere $\left(\mathrm{d} T \mathrm{~d} z^{-1}=-0.5 \mathrm{~K}(100 \mathrm{~m})^{-1}\right)$. Still more clouds build up in these simulations over wet soils, but the feedback remains positive (not shown).

The difference between precipitation and evaporation is largest for $S=40 \%$ and decreases both for higher and lower soil moisture values. Furthermore, it decreases for decreasing atmospheric stability. This means that the atmospheric moisture forcing (i.e. relaxation) is stronger over drier soils and stable atmospheric conditions. In the soil, the relaxation is, however, largest for wet soils, for which runoff is largest. It increases also marginally for stable compared to unstable atmospheric conditions. Figure $5(\mathrm{~d})$ shows mean ET and precipitation averaged over the 3 days following the transition from CTL to UNSTABLE in transient experiments. ET increases with soil moisture, similar to what is observed in the state of diurnal equilibrium. For precipitation, however, mean amounts are reduced over wet soil. This reduction primarily results from a delayed trigger of moist convection over wet soils. Thus, during such transient phases, our framework can produce a negative soil moisture-precipitation feedback.

Figure 6 shows domain mean profiles of relative humidity at 0000 and 1200 UTC. The boundary layer is considerably drier over dry soils than over wet soils and the height of the two maxima in relative humidity (the lower one coinciding with the top of the boundary layer, the upper one coinciding with the cloud layer visible in Figure 3) are situated higher for drier soils. This upward shift is also reflected in the upward shift of cloud bases. The increase of PBL moisture content between $S=60 \%$ and $80 \%$ reduces the saturation deficit most prominently for STABLE. This reduction is, however, not sufficient to reduce evaporation and to enter the second pathway into a negative soil moisture precipitation feedback (see section 2.3).

\subsection{Spatial pattern of feedback}

Looking at spatial patterns of the precipitation amounts, large differences between the simulations are visible. Figure 7 shows precipitation accumulated over days 16-30 and soil saturation at a depth of $2.5 \mathrm{~cm}$ averaged over the same period. Precipitation shows an inhomogeneous, spotty distribution of elongated patches of increased values with a size of about 20 grid points $(\hat{=} 44 \mathrm{~km})$ in the prevailing zonal flow direction. This indicates that locations where precipitation fell during the previous days favour the occurrence of new precipitation. Locations with high precipitation amounts furthermore coincide with spots of wet soil. Calculated Pearson correlation coefficients between mean precipitation and mean soil moisture range from 0.67 for $80 \_$CTL to 0.84 for 40_CTL.

As described in several studies (e.g. Emori, 1998; Baker et al., 2001; Pielke, 2001; Taylor et al., 2010), soil moisture gradients play an important role in the triggering of convection. Emori (1998) found a negative soil moisture-precipitation feedback at small spatial scales $(\mathcal{O}$ $(10 \mathrm{~km}))$ in idealized 2D experiments. The observationally based study of Taylor et al. (2011) reached the same conclusion. Over dry soils, moisture gradients induced local thermal circulations leading to maximum precipitation 

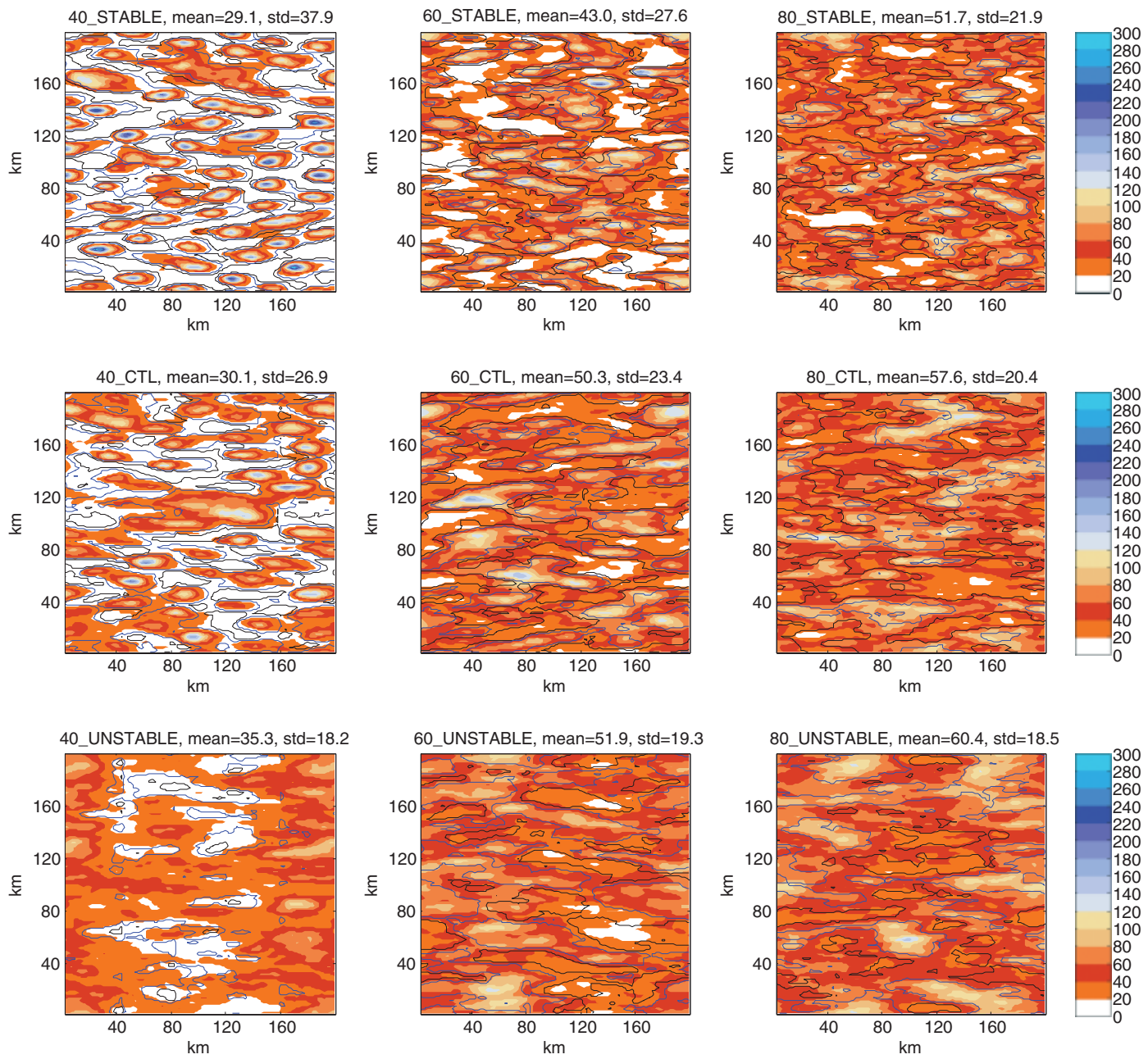

Figure 7. Spatial distributions of precipitation accumulated over days 16-30 of the simulation (colour shade, mm) and soil moisture saturation averaged over days 16-30 at a depth of $2.5 \mathrm{~cm}$ (contour lines) for the main set of simulations. The blue contours correspond to the $40 \%$ (left column), $60 \%$ (middle column) and $75.5 \%$ (right column) level and the black contour to the $35 \%, 58 \%$ and $75 \%$ level, respectively. There is a correlation between positive soil moisture and precipitation anomalies.

over dry soil patches. Baker et al. (2001) found a preferred occurrence of heavy precipitation over existing wet soil. In the later stage of a convective cell, the amount of soil moisture furthermore regulates the growth of the cell by reducing the height of the LFC (e.g. Clark et al., 2004; Taylor et al., 2010). Taylor and Ellis (2006), in contrast, document a dependency of the feedback on the length-scale of the anomaly with a negative feedback for wet patches with an elongation of more than $37 \mathrm{~km}$. Our simulations exhibit a pronounced pattern, and we find that thermal circulations develop with subsidence over negative soil moisture gradients along the flow direction and rising motion over positive soil moisture gradients. Over wet patches, the stratification is more stable and CIN values are larger. The triggering of convective cells occurs in conjunction with the rising motion along the positive soil moisture gradients. The triggered convective cells are advected with the flow and precipitate, when they pass over a wet patch (not shown). In our simulations, the aggregation of water in preferred locations is most pronounced in the 40_STABLE simulation, where the spatial standard deviation of precipitation is almost as large as the mean value. The spatial variability decreases both for more unstable atmospheres and for wetter soils. This indicates that the described mechanisms could be especially important in semi-arid regions and under a strong stratification. Overall,
Figure 7 shows that there is not only a domain-mean positive precipitation feedback, but that spatial variations develop that support the existence of a local positive feedback acting at scales of $\mathcal{O}(40 \mathrm{~km})$. Thus our results agree with several previous studies emphasizing the significance of processes acting on scales of the order of a few tens of kilometres. The described feedback is further investigated in Froidevaux et al. (pers. comm., 2012).

\subsection{Precipitation intensity}

Not only mean precipitation amounts but also precipitation intensities are affected by atmospheric stability and soil moisture content. Figure 8 shows the corresponding histograms of hourly precipitation sums. Since the simulations over dry soils trigger precipitation less often (independently of the atmospheric stability), we normalized Figure 8 by the total number of rainy grid points $(\geq 0.5$ $\left.\mathrm{mm} \mathrm{h}^{-1}\right)$. Simulations over domain-mean wet soils show strongest intensities. Over wet soils more water is stored in the atmosphere to form precipitation (see Table 3). Over dry soils, precipitation more commonly falls through dry air and more precipitation may evaporate. This is also reflected in stronger convective downdrafts over dry soils (not shown). With respect to the different stabilities, 

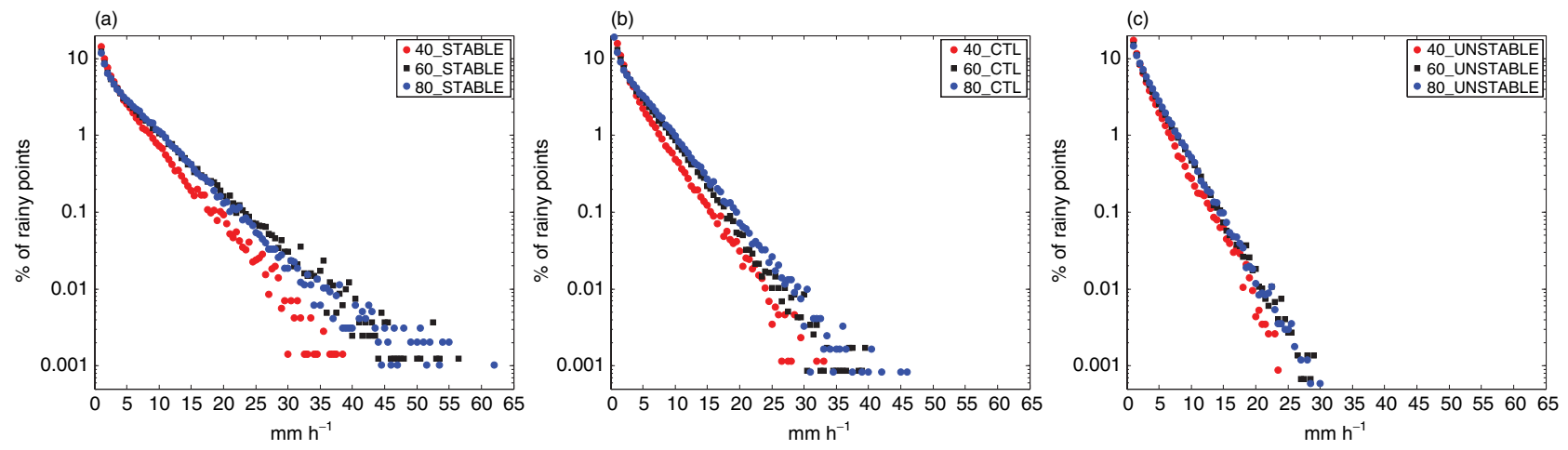

Figure 8. Logarithmic histogram of hourly precipitation sums collected at each grid point of the domain over the time period of days $16-30$ for (a) STABLE, (b) CTL and (c) UNSTABLE for $S=40 \%$ (red), $60 \%$ (black) and $80 \%$ (blue). Bins are $0.5 \mathrm{~mm} \mathrm{~h}^{-1}$ wide. Results are normalized with the number of rainy grid points.

Table 3. Equilibrium values of CAPE $\left(\mathrm{J} \mathrm{kg}^{-1}\right)$ at $1100 \mathrm{UTC}, \mathrm{CIN}\left(\mathrm{J} \mathrm{kg}^{-1}\right)$ at 0600 UTC and precipitable water averaged over the diurnal cycle $(\mathrm{mm})$. The first two characters of the simulation names refer to the volumetric soil moisture profiles depicted in Figure 1(b).

\begin{tabular}{lccc}
\hline Simulation name & $\begin{array}{c}\text { CAPE } \\
\left(\mathrm{J} \mathrm{kg}^{-1}\right)\end{array}$ & $\begin{array}{c}\text { CIN } \\
\left(\mathrm{J} \mathrm{kg}^{-1}\right)\end{array}$ & $\begin{array}{c}\text { pw } \\
(\mathrm{mm})\end{array}$ \\
\hline 20_STABLE & 55.6 & 0 & 16.3 \\
40_STABLE & 1030 & 198 & 32.7 \\
60_STABLE & 1280 & 104 & 32.7 \\
80_STABLE & 1420 & 68.5 & 34.2 \\
20_CTL & 137 & 0.544 & 13.8 \\
40_CTL & 1040 & 248 & 25.6 \\
60_CTL & 1040 & 195 & 26.3 \\
80_CTL & 1150 & 151 & 26.5 \\
20_UNSTABLE & 198 & 2.09 & 11.4 \\
40_UNSTABLE & 927 & 251 & 19.4 \\
60_UNSTABLE & 969 & 173 & 20.5 \\
80_UNSTABLE & 993 & 116 & 20.8 \\
\hline
\end{tabular}

precipitation intensities are highest for the STABLE profile. CAPE values are increased and CIN values are decreased, thus facilitating the higher rain rates.

\subsection{Triggering of convection}

Figures 3-7 underline the existence of a positive soil moisture-precipitation feedback in our system as expected from balance considerations (see section 2.3). It is interesting to compare this against predictions based on thermodynamic indices. As pointed out by Findell and Eltahir (2003a), deep convection is triggered when the descending LFC meets the top of the PBL. This has been confirmed by Schlemmer et al. (2011). Over wet soils this is achieved by a direct moistening of the atmosphere through latent heat fluxes, leading to an increase of the equivalent potential temperature $\theta_{\mathrm{e}}$ in the $\mathrm{PBL}$ and a resulting lowering of the LFC. Over dry soils, the soil cannot meet the atmospheric demand and the available energy will be passed into sensible heat flux, leading to a warming and subsequent deepening of the PBL. Whether LFC fall or PBL growth is more effective in triggering deep convection depends on the stability and moisture content of the lower troposphere.

The LFC, lifting condensation level (LCL), the PBL height and CIN values of our simulations are shown in Figure 9. For each soil moisture and stability class, the model attains a state where deep convection is triggered. Looking at the time evolution of LFC and PBL height, we see that for drier soils boundary layer growth is favoured, whereas for more moist soils the descent of the LFC dominates. In a more unstable atmosphere, the LFC is brought down more efficiently than in a stable atmosphere. The triggered convection then redistributes accumulated PBL moisture in the atmosphere, rendering a decrease of ET with increasing soil moisture impossible in our framework, as described in section 2.3.

\subsection{Additional sensitivity experiments}

Above we have found that our simulation strategy yields a positive soil moisture precipitation feedback in all cases investigated. Here we study the sensitivity of this result. To further assess the importance of the evapotranspiration in determining the precipitation response in our diurnal equilibrium framework (see section 2), we perform simulations with altered ET as well as different wind speed and soil type. The additional experiments are only performed for the simulations using the STABLE profile, as in these experiments the triggering of convection is most critical. Values for mean precipitation amounts and ET are shown in Figure 5(b, c) and together with surface fluxes of sensible and latent heat are summarized in Table 4.

Wind speed has a strong influence on the evaporation of water from the surface into the atmosphere, as it controls turbulence and thereby affects potential evaporation. Hence a set of simulations with the prescribed background wind speeds decreased to $10 \%$ of the original value over the whole atmospheric column is performed, named STABLE_CALM. Resulting precipitation amounts as a function of soil moisture are shown in Figure 5(c) by the dashed line. Figure 5 also shows the situation for our reference simulations. The new simulations still sustain a positive feedback, but of slightly weaker strength. This is not surprising: the reduction in wind speed reduces ET for a given soil moisture content by transferring the available energy into $H$, but cannot shut down ET (see section 2). Looking at the modelled Bowen ratio, there is hardly any difference between the simulations using different wind speeds (not shown). The reduction in modelled boundary layer wind speed is, moreover, small (maximum $-2 \mathrm{~m} \mathrm{~s}^{-1}$ during the time of maximum convective activity), as it becomes independent of the prescribed background profile due to the height-dependent formulation of the relaxation. 

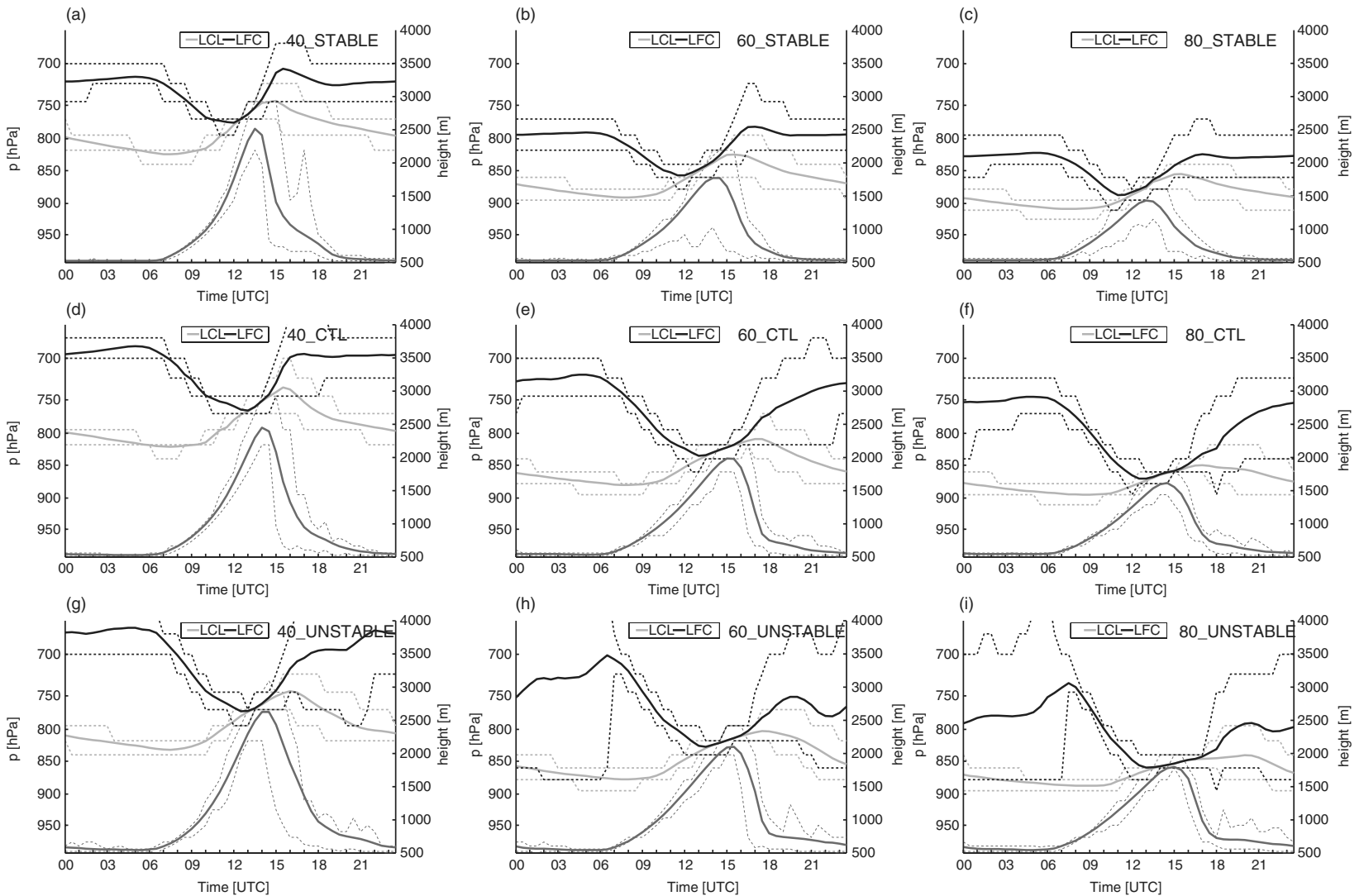

Figure 9. Height of the domain mean value (solid line) and 10th and 90th percentile (dashed lines) of the LCL (light-grey line), LFC (black line) and boundary layer height (dark-grey line) averaged over days 16-30 of the simulation for the set of nine simulations.

Table 4. The same as Table 2 but for the additional sensitivity tests.

\begin{tabular}{|c|c|c|c|c|}
\hline Simulation name & $\begin{array}{l}\text { Precipitation sum } \\
\left(\mathrm{mm} \mathrm{d}^{-1}\right)\end{array}$ & $\begin{array}{l}Q \\
\left(\mathrm{~W} \mathrm{~m} \mathrm{~m}^{-2}\right)\end{array}$ & $\begin{array}{l}E \\
\left(\mathrm{~W} \mathrm{~m}^{-2}\right)\end{array}$ & $\begin{array}{l}H \\
\left(\mathrm{~W} \mathrm{~m}^{-2}\right)\end{array}$ \\
\hline 40_STABLE_sand & 2.84 & 150 & 127 & 23.3 \\
\hline 60_STABLE_sand & 3.54 & 146 & 131 & 15.1 \\
\hline 80_STABLE_sand & 3.66 & 148 & 132 & 15.3 \\
\hline 40_STABLE_v & 2.02 & 148 & 106 & 41.5 \\
\hline 60_STABLE_v & 3.14 & 150 & 124 & 26.0 \\
\hline 80_STABLE_v & 3.50 & 146 & 129 & 17.0 \\
\hline 40_STABLE_PAR & 1.82 & 147 & 104 & 43.0 \\
\hline 60_STABLE_PAR & 3.02 & 149 & 124 & 25.6 \\
\hline 80_STABLE_PAR & 3.24 & 147 & 132 & 15.6 \\
\hline 40_STABLE_DRY & 1.47 & 147 & 108 & 39.4 \\
\hline 60_STABLE_DRY & 2.43 & 148 & 124 & 24.1 \\
\hline 80_STABLE_DRY & 2.79 & 152 & 136 & 15.6 \\
\hline 40_STABLE_WET & 2.40 & 152 & 106 & 45.8 \\
\hline 60_STABLE_WET & 3.44 & 148 & 123 & 24.5 \\
\hline 80_STABLE_WET & 3.78 & 147 & 132 & 15.3 \\
\hline
\end{tabular}

In the next set of simulations, called STABLE_SAND, we change the soil type from loam to sand. For sandy soils, water is evaporated more easily since the hydrologic conductivity parameter controlling bare soil evaporation is larger in sand than loam soil by a factor of nine. Furthermore the field capacity $\Theta_{\mathrm{fc}}$ of sand is smaller than for loam $\left(\Theta_{\mathrm{fc} \text {,sand }}=54 \%\right.$, $\Theta_{\mathrm{fc}, \text { loam }}=75 \%$ saturation $)$, meaning that the dependency of transpiration on the available soil water reaches its maximum at smaller volumetric soil water contents (described by the $F_{\text {wat }}$ function in the Jarvis (1976) approach; see Eq. (4)). Comparing the diurnal cycles of convection, the change from loam to sand soil roughly equals a moistening of the loam soil by $20 \%$. In addition, over sand the simulations with
$S=60 \%$ and $S=80 \%$ look nearly identical, as evaporation is at the potential rate here and cannot be increased any further, thus preventing an even further positive soil moisture-precipitation feedback. Precipitation nevertheless increases marginally, going from $S=60 \%$ to $80 \%$. For low soil moisture amounts ET decreases and, as expected, precipitation amounts decrease. ET and the precipitation amounts, nevertheless, remain larger than over loam, as evaporation is limited by the availability of water, which is higher over sand soil.

The formation of mid-level clouds observed in Figure 3 influences transpiration by a reduction of photosynthetically active radiation (PAR). In the formulation of transpiration, 
this is considered in the function $F_{\text {rad }}$ (see Eq. (4)). For PAR values below $100 \mathrm{~W} \mathrm{~m}^{-2}$ a linear decrease of $F_{\text {rad }}$ towards zero at PAR $=0$ is assumed (see Eq. (5)). To investigate how sensitive our results are to this threshold, we increase the threshold $\mathrm{PAR}_{\text {crit }}$ below which transpiration is sensitive to PAR to $200 \mathrm{~W} \mathrm{~m}^{-2}$ in experiment STABLE_PAR. Resulting ET and precipitation (Figure 5(c), dash-dotted line) are qualitatively in line with the previous results.

In a further simulation, called STABLE_crsmin, we lower the parameter for the minimum stomatal resistance $r_{\text {min }}$ in the formulation of transpiration (see Eq. (4)) from 150 to $50 \mathrm{~s} \mathrm{~m}^{-1}$. This change in model physics is also one of the perturbations applied in the project 'short-range ensemble forecasting system' (SREPS) using the COSMO model (Marsigli, 2009). Lowering $r_{\min }$ should allow for more ET. ET and precipitation for 60_STABLE_crsmin and 80_STABLE_crsmin are very close. Precipitation increases for $S=60 \%$ from 2.88 to $3.35 \mathrm{~mm} \mathrm{~d}^{-1}$, while for $S=80 \%$ the increase in precipitation is very small (not shown). The positive soil moisture-precipitation feedback remains, however.

\subsection{Role of atmospheric humidity}

As a last sensitivity experiment we conduct two additional sets of simulations using drier (simulations STABLE_DRY) and wetter (simulations STABLE_WET) atmospheric humidity profiles. Findell and Eltahir (2003a) pointed out that the humidity content of the lower atmosphere has a strong influence on whether a dry or a wet soil is more efficient in triggering convection. Values for lower-tropospheric humidity were decreased (increased) by $20 \%$ and upper-tropospheric humidity by $10 \%$, resulting in relative humidity profiles with $90 \%$ and $50 \%$ for the simulation STABLE_WET, and $50 \%$ and $30 \%$ for STABLE_DRY (see Table 1). These atmospheric profiles fall into the categories 'wet soil advantage' and 'dry soil advantage', respectively, as defined in Findell and Eltahir (2003a). As seen in Figure 5(b) and Table 2, diurnal equilibrium values for precipitation are slightly decreased (increased) for STABLE_DRY (STABLE_WET), but the overall increase of precipitation with soil moisture is consistent with the previously observed positive soil moisture-precipitation feedback. ET is nearly identical and nearly independent of the atmospheric humidity. A slight reduction due to the decrease of the saturation deficit in STABLE_WET can be seen. This relatively low sensitivity of ET to the prescribed relative humidity of the atmosphere has been described in Schlemmer et al. (2011). It results from the redistribution of moisture in the atmosphere in the state of diurnal equilibrium by ongoing convection.

\subsection{Approach to equilibrium}

To infer how long it takes the system to reach equilibrium, we perform a set of simulations where the system is first run to diurnal equilibrium, and then an instantaneous perturbation is applied. The perturbations consist of a change from one to another atmospheric reference stability profile, or from one to another soil moisture content (e.g. $S=60 \%$ to $S=40 \%$ or $80 \%$ saturation). Spatial inhomogeneities are thereby preserved across this transition. After the perturbation is applied, it takes about 5-10 days to recover a state of diurnal equilibrium, depending on the variable considered and the change applied. The system adapts more quickly to changes in soil moisture than to changes in the atmospheric stability. Moreover, unstable atmospheric profiles adapt more quickly to changes in soil moisture.

To Figure out how long the system retains the equilibrium state, we conduct simulations where the relaxation is switched off after 30 days both in the atmosphere and in the soil. The diurnal cycle on the two following days is compared to the equilibrium diurnal cycle including relaxation. Simulations with and without relaxation are very similar. Thus the relaxation terms do not strongly affect the heat and moisture budgets. They are only small correction terms that are applied in order to keep the model from drifting to a different state. They do not significantly affect the dynamics of the system.

\section{Discussion}

We have shown that both the atmospheric stability and the moisture content of the soil have a strong influence on the diurnal cycle of convection. In a stable atmosphere, convection tends to be suppressed but ultimately results in more violent outbreaks of convective activity and higher precipitation rates. In a weakly stratified environment, convection can develop more easily and moisture is quickly redistributed in the atmosphere. Over dry loam soils $(S \leq 60 \%)$ the formation of clouds and precipitation is limited as the soil cannot meet atmospheric demand. Over wet soil, more moisture is evaporated from the soil, resulting in more clouds and precipitation. An increase in precipitation with increasing soil moisture, i.e. a positive soil moisture-precipitation feedback, resulted in all experiments, and is a robust feature for the current simulation strategy.

The current study includes no topography; thus we miss some important processes in the build-up of convection and precipitation. As described in Hohenegger et al. (2009), valley circulations may be amplified or damped by dry and wet soils, respectively, with pronounced implications on afternoon convection. In addition, we do not include largescale water bodies as, for example, in Cook et al. (2006), that modify the patterns of moisture convergence. In our idealized framework we are, moreover, unable to span the full range of possible interactions. Most importantly, we cannot reproduce the influence of large-scale processes such as subsidence that suppresses convection and favours the development of stable layers. For example, this is frequently observed in the subsiding branch of the Hadley circulation where over cold ocean surfaces the formation of stratocumulus clouds is favoured and over continental regions arid regions appear.

A possibility to increase PBL moisture in our framework would be to suppress the triggering of convection by the presence of such stable layers. It is, however, difficult to realize such a mechanism in the current set-up. We did put considerable effort into including subsidence in different ways. In a first approach, we imposed low-level divergence and upper-level convergence on to the horizontal wind field, resulting in subsiding motion with a downward velocity of up to $\approx 2 \mathrm{~mm} \mathrm{~s}^{-1}$. This resulting subsidence dominated over the surface fluxes, dried and warmed the atmosphere and reduced precipitation amounts over both wet and dry soils. In a second approach we added vertical advective tendencies resulting from a prescribed subsidence profile 
on the tendencies of temperature, specific humidity and horizontal winds directly (e.g. Siebesma et al., 2003). These experiments delivered no directly interpretable answers. In both approaches a stable cloud layer did not evolve, as clouds broke up after a few days and precipitation started to fall. The constant input of energy into the system through radiation and the strong turbulent fluxes from the land surface counteract a strong stabilization.

Moreover, the presented framework addresses diurnal convection situations in summertime only. Changing weather situations, characterized by transience, are not captured. Systematic experiments including specific timedependent advection or forcings are, however, beyond the scope of this paper. Nevertheless, simulations that include some pseudo-transience indicate that transience is potentially relevant.

\section{Summary}

The influence of soil moisture and atmospheric static stability on the diurnal cycle of convection and precipitation has been investigated in an idealized cloud-resolving modelling framework in a state of diurnal equilibrium. We think that the framework presented can give helpful insights into the longer-term behaviour of the coupled summertime land-atmosphere system. We performed a set of simulations with relative soil moisture saturations of $20 \%, 40 \%, 60 \%$ and $80 \%$ using atmospheric profiles of different stability (stable, control and unstable). In all simulations with $S \geq 40 \%$ deep, precipitating convection is triggered every day:

- In weak and intermediate stable atmospheres very deep convection develops. For these conditions, an increase in soil moisture causes an increase in latent heat fluxes and precipitation.

- For strong atmospheric stabilities, an increase in soil moisture leads to the formation of clouds in the morning hours that shield incoming radiation and trap outgoing long-wave radiation. The overall influence on the net available surface radiation is a slight increase over wet soils. Thus latent heat fluxes increase for increased soil moisture, leading to larger precipitation amounts.

In both cases, the soil moisture-precipitation feedback is therefore positive. Sensitivity experiments on the moisture content of the atmosphere, the soil type used, the wind speed and the parametrization of transpiration confirm the increase of diurnal equilibrium precipitation with increasing soil moisture.

The spatial distribution of precipitation shows very inhomogeneous patterns that are most pronounced over dry soils and for stable stratifications. The occurrence of rainfall is favoured over wet soil patches, indicating also a positive feedback at small spatial scales.

Overall, the framework developed gives deeper insights into the longer-term behaviour of the coupled summertime land-atmosphere system. The main limitation is the restriction to quasi-steady configurations. Further work will be needed to address the atmospheric response to soil moisture in more transient settings.

\section{Acknowledgements}

This project has been partly funded by the Swiss National Science Foundation through NCCR Climate. The necessary computer resources for the simulations were provided by the Swiss National Supercomputing Center (CSCS) in Manno. We are indebted to the COSMO consortium and the CLM community for providing access to and support of the CCLM model. We would particularly like to acknowledge technical support by staff of MeteoSwiss and the Center for Climate Systems Modeling (C2SM). Furthermore, we wish to thank Bjorn Stevens for providing useful comments on the modelling framework.

\section{References}

Alfieri L, Claps P, D’Odorico P, Laio F, Over TM. 2008. An analysis of the soil moisture feedback on convective and stratiform precipitation. J. Hydrometeorol. 9: 280-291.

Baker RD, Lynn BH, Boone A, Tao WK, Simpson J. 2001. The influence of soil moisture, coastline curvature, and land-breeze circulations on sea-breeze-initiated precipitation. J. Hydrometeorol. 2: 193-211.

Baldauf M, Seifert A, Förstner J, Majewski D, Raschendorfer M, Reinhardt T. 2011. Operational convective-scale numerical weather prediction with the COSMO model: description and sensitivities. Mon. Weather Rev. 139: 3887-3905.

Brown ME, Arnold DL. 1998. Land-surface-atmosphere interactions associated with deep convection in Illinois. Int. J. Climatol. 18: $1637-1653$.

Clark DB, Taylor CM, Thorpe AJ. 2004. Feedback between the land surface and rainfall at convective length scales. J. Hydrometeorol. 5: 625-639.

Cook BI, Bonan GB, Levis S. 2006. Soil moisture feedbacks to precipitation in southern Africa. J. Climate 19: 4198-4206.

Davin EL, Stoeckli R, Jaeger EB, Levis S, Seneviratne S. 2011. COSMOCLM2: a new version of the COSMO-CLM model coupled to the Community Land Model. Clim. Dynam. 37: 1889-1907.

Denmead OT, Shaw RH. 1962. Availability of soilwater to plants as affected by soil moisture content and meteorological conditions. Agron. J. 54: 385-390.

Dickinson RE. 1984. Modeling evapotranspiration for three-dimensional global climate models. In Climate Processes and Climate Sensitivity, Hansons JE, Takahashi T (eds). AGU: Washington, DC; 58-72.

Dirmeyer PA, Schlosser CA, Brubaker KL. 2009. Precipitation, recycling, and land memory: an integrated analysis. J. Hydrometeorol. 10: $278-288$.

D'Odorico P, Porporato A. 2004. Preferential states in soil moisture and climate dynamics. Proc. Natl Acad. Sci. USA 101: 8848-8851.

Doms G, Förstner J. 2004. Development of a kilometer-scale NWPSystem: LMK. COSMO Newsletter No. 4: 159-167. http://www. cosmo-model.org/content/model/documentation/newsLetters/news Letter04/chp9-5.pdf

Ek MB, Holtslag AAM. 2004. Influence of soil moisture on boundary layer cloud development. J. Hydrometeorol. 5: 86-99.

Ek M, Mahrt L. 1994. Daytime evolution of relative humidity at the boundary-layer top. Mon. Weather Rev. 122: 2709-2721.

Eltahir EAB. 1998. A soil moisture-rainfall feedback mechanism. 1. Theory and observations. Water Resour. Res. 34: 765-776.

Emori S. 1998. The interaction of cumulus convection with soil moisture distribution: an idealized simulation. J. Geophys. Res. 103(D8): $8873-8884$.

Enthekabi D, Rodriguez-Iturbe I, Bras R. 1992. Variability in large- scale water balance with land-surface-atmosphere interactions. J. Climate 5: 798-813.

Findell KL, Eltahir EAB. 2003a. Atmospheric controls on soil moisture: boundary layer interactions. Part I. Framework development. J. Hydrometeorol. 4: 552-569.

Findell KL, Eltahir EAB. 2003b. Atmospheric controls on soil moisture-boundary layer interactions: three-dimensional wind effects. J. Geophys. Res. 108(D8): 8385.

Findell KL, Gentine P, Lintner BR, Kerr C. 2011. Probability of afternoon precipitation in eastern United States and Mexico enhanced by high evaporation. Nature Geosci. 4: 434-439.

Fischer EM, Seneviratne SI, Lüthi D, Schär C. 2007a. Contribution of land-atmosphere coupling to recent European summer heat waves. Geophys. Res. Lett. L06707, DOI: 1029/2006GL029068. 
Fischer EM, Seneviratne SI, Vidale PL, Lüthi D, Schär C. 2007b. Soil moisture-atmosphere interactions during the 2003 European summer heat wave. J. Climate 20: 5081-5099.

Garrett AJ. 1982. A parameter study of interactions between convective clouds, the convective boundary layer, and a forested Surface. Mon. Weather Rev. 110: 1041-1059.

Heise E, Lange M, Ritter B, Schrodin R. 2003. Improvement and validation of the multi-layer soil model. COSMO Newsletter No. (3): 198-203. http://www.cosmo-model.org/content/model/ documentation/newsLetters/newsLetter03/cnl3-chp9-12.pdf

Hohenegger C, Brockhaus P, Schär C. 2008. Towards climate simulation at cloud-resolving scales. Meteorol. Z. 17: 383-394.

Hohenegger C, Brockhaus P, Bretherton CS, Schär C. 2009. The soil moisture-precipitation feedback in simulations with explicit and parameterized convection. J. Climate 22: 5003-5020.

Jaeger EB, Stöckli R, Seneviratne S. 2009. Analysis of planetary boundary layer fluxes and land-atmosphere coupling in the Regional Climate Model CLM. J. Geophys. Res. 114: D17106, DOI: 10.1029/2008JD011658.

Jarvis PG. 1976. The interpretation of the variations in leaf water potential and stomatal conductance found in canopies in the field. Phil. Trans. R. Soc. Lond. B 273: 593-610.

Klemp J, Wilhelmson R. 1978. Simulation of 3-dimensional convective storm dynamics. J. Atmos. Sci. 35: 1070-1096.

Koster RD, Dirmeyer PA, Guo Z, Bonan G, Chan E, Cox P, Gordon CT, Kanae S, Kowalczyk E, Lawrence D, Liu P, Lu CH, Malyshev S, McAvaney B, Mitchell K, Mocko D, Oki T, Oleson K, Pitman A, Sud YC, Taylor CM, Verseghy D, Vasic R, Xue Y, Yamada T. 2004. Regions of strong coupling between soil moisture and precipitation. Science 305: 1138-1140.

Marsigli C. 2009. COSMO Priority Project 'Short Range Ensemble Prediction System' (SRPES): Final Report. Technical Report 13, COSMO.

Pielke RA Sr. 2001. Influence of the spatial distribution of vegetation and soils on the prediction of cumulus Convective rainfall. Rev. Geophys. 39: $151-177$.

Santanello JA, Friedl MA, Ek MB. 2007. Convective planetary boundary layer interactions with the land surface at diurnal time scales: diagnostics and feedbacks. J. Hydrometeorol. 8: 1082-1097.

Schär C, Lüthi D, Beyerle U, Heise E. 1999. The soil-precipitation feedback: a process study with a regional climate model. J. Climate 12: $722-741$.

Schlemmer L, Hohenegger C, Schmidli J, Bretherton CS, Schär C. 2011. An idealized cloud-resolving framework for the study of midlatitude diurnal convection over land. J. Atmos. Sci. 68: 1041-1057.

Seneviratne SI, Lüthi D, Litschi M, Schär C. 2006. Land-atmosphere coupling and climate change in Europe. Nature 443: 205-209.

Siebesma AP, Bretherton CS, Brown A, Chlond A, Cuxart J, Duynkerke PG, Jiang H, Khairoutdinov M, Lewellen D, Moeng CH, Sanchez E, Stevens B, Stevens DE. 2003. A large eddy simulation intercomparison study of shallow cumulus convection. J. Atmos. Sci. 60: $1201-1219$.

Steppeler J, Doms G, Schattler U, Bitzer HW, Gassmann A, Damrath U, Gregoric G. 2003. Meso-gamma scale forecasts using the nonhydrostatic model LM. Meteor. Atmos. Phys. 82: 75-96.

Su H, Shuyi SC, Bretherton CS. 1999. Three-dimensional week-long simulations of toga COARE convective systems using the mm5 mesoscale model. J. Atmos. Sci. 56: 2326-2344.

Taylor CM, Ellis RJ. 2006. Satellite detection of soil moisture impacts on convection at the mesoscale. Geophys. Res. Lett. 33: L03404, DOI: 10.1029/2005GL025252.

Taylor CM, Harris PP, Parker DJ. 2010. Impact of soil moisture on the development of a Sahelian mesoscale convective system: a case study from the AMMA Special Observing Period. Q. J. R. Meteorol. Soc. S1: $456-470$.

Taylor CM, Gounou A, Guichard F, Harris PP, Ellis RJ, Couvreux F, De Kauwe M. 2011. Frequency of Sahelian storm initiation enhanced over mesoscale soil-moisture patterns. Nature Geosci. 4: 430-433.

van den Hurk B, van Meijgaard E. 2010. Diagnosing land-atmosphere interaction from a regional climate model simulation over West Africa. J. Hydrometeorol. 11: 467-481.

van Heerwarden CC, Vila-Guerau de Arellano J, Moene AF, Holtslag AAM. 2009. Interactions between dry-air entrainment, surface evaporation and convective boundary-layer development. Q. J. R. Meteorol. Soc. 135: 1277-1291.

Wicker L, Skamarock W. 2002. Time-splitting methods for elastic models using forward time schemes. Mon. Weather Rev. 130: 2088-2097.

Zubler EM, Lohmann U, Lüthi D, Schär C. 2011. Intercomparison of aerosol climatologies for use in a regional climate model over Europe. Geophys. Res. Lett. 38: L15705, DOI: 10.1029/2011GL048081. 